\title{
TROPA DE ELITE: PERIGOSAS AMBIGUIDADES
}

\section{Paulo Menezes*}

\author{
Para Ana Lúcia
}

Tropa de elite 2 (José Padilha, 2010) alcançou o índice de filme brasileiro mais assistido de todos os tempos, com 11 milhóes de espectadores nos cinemas, superando Dona Flor e seus dois maridos, que detinha este recorde desde 1976, com 10,73 milhões de espectadores. ${ }^{1}$ Tamanho êxito deve-se, em grande parte, ao imenso e polêmico sucesso de seu predecessor, Tropa de elite (2007), no qual se viu a materialização empírica mais vidente daquilo que Ian Jarvie chamou de correntes de opinião (Jarvie, 1974), que divulgam um filme por canais que desafiam os meios tradicionais de propaganda e publicidade por meios informais como a divulgação boca-a-boca e, mais modernamente, pelos vários canais criados pela internet (facebook, blogs, twitter etc.). Ao mesmo tempo, esta sequência

* Agradeço o CNPq pelo apoio a esta pesquisa.

Artigo recebido em 04/11/2011

Aprovado em 14/05/2012 não proporcionou nem de longe o debate suscitado pelo primeiro filme, mostrando que, se por um lado o sucesso do primeiro induziu o enorme público do segundo, este último também apoiado em uma imensa campanha publicitária, o mesmo não aconteceu em relação à proliferação de críticas, positivas e negativas, que o primeiro ensejou. Nessa direção, para se compreender o sucesso de ambos os filmes, devem-se examinar as questões deixadas em aberto pelo primeiro, que possibilitaram não só a existência fílmica de sua continuação, mas também o enorme público que ele atraiu aos cinemas, independentemente de sua baixa repercussão crítica nos meios de comunicação.

Tropa de elite foi o maior sucesso do cinema nacional brasileiro do ano de 2007. Sucesso realmente avassalador teve, segundo estimativas, algo em torno de 13,5 milhôes de espectadores, sendo que por volta de 11 milhões viram o filme por meio de cópias piratas baixadas da internet ou vendidas 
por camelôs (cf. Boscov, 2007, p. 86), cifra que, se fosse computada como público, tornaria Tropa de elite, e não sua continuação, o filme brasileiro mais assistido de todos os tempos. Independentemente disso, em 2007 o filme alcançou, em termos de bilheteria, o lugar normalmente ocupado por filmes da Xuxa e dos Trapalhóes durante toda a década. Primazia que, naquele ano, foi apenas desafiada por filmes realizados a partir de séries televisivas e produzidos pela Globo filmes. Assim, Tropa de elite teve 2,5 milhões de espectadores nos cinemas, deixando para trás o segundo colocado, $A$ grande família, com 2 milhões de espectadores, e sucessivamente Primo Basilio (839 mil), A turma da Mônica (631 mil) e Xuxa gêmeas (572 mil), os dois últimos dirigidos ao público infantil. Além disso, ficou em sétimo lugar na avaliação geral das bilheterias, e, somando-se também o público pressuposto que viu o filme via internet, Tropa de elite também deixou para trás os blockbusters estrangeiros que são sempre os campeões de bilheteria no Brasil: Homem Aranha 3 (6,1 milhôes), Shrek terceiro (4,8 milhōes), Harry Potter 5 (4,3 milhões), Piratas do Caribe 3 (3,8 milhões), Uma noite no museu (3 milhōes) e 300 (2,7 milhões). ${ }^{2}$

O assunto de Tropa de elite, entretanto, não era propriamente inovador. A relação entre pobreza, tráfico de drogas e repressão policial já havia ocupado as telas dos cinemas não só em documentários, como Notícias de uma guerra particular (João Moreira Salles, Brasil, 1999), mas também com filmes de "ficção" de grande sucesso, como Cidade de Deus (Fernando Meirelles, Brasil, 2002), que teve também longa carreira internacional.

A proposta deste texto é de investigar as possíveis razões que fizeram um filme que tinha tudo para ser apenas mais um sobre pobreza e violência se tornar o centro das atenções e dos debates de uma parcela considerável da população brasileira, variando de uma defesa absoluta e reacionária (cf. Azevedo, 2007) a uma crítica violenta e extremada (cf. Bloch, 2007). São as mais variadas posições entre esses dois pontos de vista antinômicos que mais me interessam. É fácil entender por que um público favorável à repressão policial a qualquer preço gostou do filme e por que um público crítico aos excessos policiais não gostou. Mas é muito mais complicado entender por que mesmo as pessoas que não legitimam o uso da violência policial saíram do filme sensibilizadas por ele, ainda que com críticas a essa postura de excesso que o filme retrata.

Retomando as colocações de Pierre Sorlin (1982, pp. 199-242) sobre cinema e ideologia e as minhas próprias reflexões anteriores sobre a epistemologia das imagens de cinema (Menezes, 2004, pp. 21-48), argumentarei que o segredo desse filme não está na análise da história em si, mas em como essa história é estruturada e contada, como os personagens sociais são construídos, que desafios são colocados para eles e que relações e hierarquias são constituídas entre os grupos sociais que o filme constrói. Argumentarei, mais especificamente, que as oscilações entre personagens estereotipados e outros mais mediados geram profundas ambiguidades no filme, ensejando leituras tão distintas.

Isto realça, indubitavelmente, o que Bazin ressaltou como sendo uma das características mais fundamentais dos cineastas que, segundo ele, "acreditavam na realidade": a recuperação no filme da ambiguidade das imagens (cf. Bazin, 1985, pp. 63-68).

De acordo com Bazin, entre os anos de 1920 e 1940 duas tendências opostas se constituíram no intenso debate das relações possíveis entre imagens, filmes e realidade. Por um lado, havia aqueles que fundavam o trabalho cinematográfico na plasticidade das imagens e nas possibilidades de constituição de sentido propostas pela montagem, a partir da herança dos expressionistas alemães (principalmente os advindos dos experimentos visuais do grupo $\mathrm{A}$ Ponte [Die Brücke]), no caso dos primeiros, e dos preceitos de Kuleshov e Eisenstein, no caso dos segundos. Eles eram, nesta acepção, os cineastas que acreditavam nas imagens, entendendo imagem como "tudo aquilo que se acresce à coisa a sua representação na tela" (Idem, p. 64). Seriam diretores, portanto, que utilizariam de maneira acentuada na construção de seus filmes elementos artificiais como cenários, iluminação e maquiagem na preparação de uma narrativa sofisticada e não naturalista realçada pelos atributos de uma montagem que articularia estes elementos em uma proposição de significados. São importantes manifestações desse tipo de proposição os cineastas conhecidos como expressionistas 
alemães (Robert Wiene e Fritz Lang, entre outros), famosos por suas propostas plásticas de vanguarda, associados àqueles que partiram das teorizaçóes de Pudovkin e Eisenstein, criador da montagem dialética das imagens, derivada das ideias de Marx segundo as quais a unidade de contrários - no caso de filmes, a contraposição de dois planos curtos - criaria um sentido radicalmente diferente daquele contido em cada um dos planos em particular.

$\mathrm{Na}$ direção oposta, estariam aqueles que Bazin chamou de cineastas que acreditam na realidade. Estes diretores, ao contrário daqueles que "acreditavam nas imagens", fundavam suas proposiçōes de sentido na recuperação visual da continuidade espaço-temporal que as pessoas experimentam em sua vida cotidiana. Nesta acepção, a montagem não deveria realizar "nenhum papel adicional a não ser o puramente negativo de inevitável eliminação de elementos de uma realidade abundante demais" (Idem, p. 66). Nesse sentido, ao contrário de planos curtos articulados por contraste, deveríamos ter planos longos, articulados de forma a se recriar para a percepção a continuidade espaço-temporal por meio de uma montagem "praticamente invisível" para o espectador. Bazin associava a isso ainda outro artifício, desta vez técnico, por meio da utilização de lentes com grande profundidade de campo, que proporcionavam tomadas abertas e profundas, criando no espectador a sensação de ver as imagens do filme da mesma maneira e ângulo que ele presencia o mundo em que vive. Portanto, "a profundidade de campo coloca o observador em uma relação com as imagens que é próxima da relação que ele mantém com a realidade. Seria justo dizer, então, que independente do conteúdo das imagens, sua estrutura é mais realista" (Idem, p. 67, grifo meu). Veremos que esta proposição é extremamente significativa na construção do personagem do capitão Nascimento, central na proposição dos sentidos do filme. Neste contexto, a continuidade espaço-temporal, que Bazin chamou de plano-sequência, associado à profundidade de campo, seriam as principais características de um cinema denominado por ele, nos anos de 1940, de neorrealismo, mas que se expressavam desta forma desde a década de 1920, por meio dos trabalhos de cineastas como Flaherty, Murnau e Stroheim. Bazin criticava as teorias de montagem por achar que "elas se opunham, essencialmente por sua própria natureza, à expressão da ambiguidade" (Idem, p. 75).

Isto ressalta aquilo que Francastel chamou de caráter alusivo das imagens, que possuem como referência primeira de proposição de sentido não a "realidade" exterior da qual parecem nascer, mas os valores culturais da sociedade na qual foram concebidas:

O fenômeno da imagem, do pensamento expresso por imagens, do espírito que pensa por imagens, são coisas que devem ser consideradas como tendo uma natureza diferente da enumeração, análise simples de uma imagem que é realmente um meio, uma análise técnica, e não um fenômeno intelectual ou um fenômeno fundado nos mecanismos da percepção. [...] A imagem existe em si mesma; ela existe essencialmente no espírito, como uma referência de cultura e não como referência de realidade (Francastel, 1983, p. 193).

As análises propostas aqui consideram os filmes - individualmente ou em grupos - como práticas significativas; elas irão estudar seus mecanismos, mas terão o dever de nunca isolar esta operação da configuração ideológica do meio social na qual ela se insere. [...] É certo que a percepção do filme pela audiência deve passar por ajustes automáticos: o público se satisfaz mais quanto menos problemas ele tem assistindo aquilo que lhe parece ter referências familiares. Mas nosso trabalho consiste precisamente em recusar tudo aquilo que é externo ao filme, retendo apenas o que é indicado na tela (Sorlin, 1977, p. 239).

Foucault deixa esta opção metodológica mais clara. Ele afirma, em L'ordre du discours, que as obras devem ser vistas como discursos e não como a Obra de um Autor, pois levar em consideração quem fala implica em um constrangimento analítico no sentido de o discurso passar a ser obrigatoriamente (e daí o constrangimento) referido ao nome do autor e a uma pretensa homogeneidade discursiva de inferição de sentidos e significados, de uma obra para a outra, e de coerência entre si: 
Acredito que existe um [outro] princípio de rarefação de um discurso. [...] Trata-se do autor. Autor aqui, evidentemente, não entendido como o indivíduo falante, que pronunciou ou escreveu um texto, mas como princípio de agrupamento do discurso, como unidade e origem de suas significações, como lugar de sua coerência (Foucault, 1971, p. 28).

Em Qu'est-ce q'un auteur?, Foucault aprofunda esta perspectiva: "o nome de um autor não é simplesmente um elemento de um discurso [...]; ele exerce em relação aos discursos certo papel: assegura uma função classificatória; um nome permite reagrupar certo número de textos, delimitá-los, excluir alguns, opô-los a outros" (Foucault, 1994, p. 798). Nesse sentido, o que Foucault denomina de função autor acaba por exercer sobre os discursos, por meio desta pretensa homogeneidade identificatória referencial, não uma iluminação esclarecedora de significações por meio de homologias, mas algo em direção oposta : "Diremos que o autor é uma produção ideológica, na medida em que possuímos uma representação invertida de sua função real. $\mathrm{O}$ autor é, portanto, a figura ideológica por meio da qual se conjura a proliferação de sentidos" (Idem, p. 811, grifo meu).

Assim, do ponto de vista analítico, para se interpretar Tropa de elite como discurso é necessário se esquecer de que se trata de um filme de um autor, portanto, uma obra de Padilha. ${ }^{3}$

Nessa direção, para tentar desvendar a enorme diversidade de interpretações que o filme gerou, para tentar entender como interpretaçôes tão disparatadas se produziram, é necessário se investigar a partir de dentro do filme, de suas imagens, no intuito de melhor compreender os sistemas relacionais ali constituídos; nas palavras de Sorlin, os conceitos que organizam sua narrativa, o posicionamento dos personagens e as hierarquias entre os grupos sociais reconstruídos para o espectador (cf. Sorlin, 1977, pp. 237-241), buscando-se desvelar sua construção, as regras que organizam o mundo projetado na tela, as estratégias sociais ali presentes, os modelos de classificação e valoração, e, portanto, de hierarquização e avaliação ali propostos, a "encenação social", construída por uma narrati- va que não se inscreve no real apesar de, às vezes, confundir-se com ele.

Um filme não é uma história nem uma duplicação do real fixada em celulose: é uma encenação social, e isto em duas direções. $\mathrm{O}$ filme constitui, em princípio, uma seleção (certos objetos e não outros) e depois uma redistribuição: ele reorganiza, a partir dos elementos tomados, no essencial, do universo ambiente, um conjunto social que, por certos aspectos, evoca o meio do qual saiu, mas que, no essencial, é dele uma retradução imaginária (Idem, p. 200, grifo meu).

As famosas regras da continuidade trabalham para estabelecer uma combinação de tomadas para obter sequência de imagens fluente, que irão dissolver a "descontinuidade visual elementar” em uma reconstrução espaço-temporal contínua. [...] Aqui a opção é primeiro estabelecer entre um fenômeno mostrado em dois planos diferentes uma relação que reproduza a "lógica natural dos fatos" e que busque, no nível da percepção, neutralizar a descontinuidade elementar (Xavier, 1984, pp. 23-24).

Ao sugerir algumas razões pelas quais um filme como este seduziu uma parcela considerável dos espectadores, independentemente das críticas que suscitou, analisarei as construções que foram realizadas pelo cineasta e que dão eixo e ossatura à sua história. Iniciarei com a identificação dos grupos sociais envolvidos na trama do filme, aparentemente a história de um capitão do BOPE (Batalhão de Operações Especiais) da polícia militar do Rio de Janeiro que busca um sucessor dentro da corporação capaz de tocar o seu trabalho para que ele possa sair da ativa; como pano de fundo, a repressão ao tráfico de drogas e a corrupção da polícia militar.

Veremos, então, quais são os conceitos gerais que fundamentam e estão por trás desta construção narrativa. O encadeamento dos argumentos irá sugerir, por fim, que Tropa de elite gerou o debate mais acirrado da história do cinema nacional por abordar um tema urgente do cotidiano da população brasileira, utilizando-se de certa ambiguidade 
na construção de seus personagens que permitiu uma interpretação diferencial a partir da diversidade dos valores culturais dos espectadores.

\section{Os "estudantes": estereótipos e metonímia social}

Esse grupo social é bem delineado pelo filme. A classe social à qual pertencem fica explícita desde suas primeiras cenas. Uma primeira pista já é dada no momento em que Matias (o policial negro) entra na sala de aula da universidade pela primeira vez, enquanto o narrador (capitão Nascimento) anuncia que, apesar de vir de camadas pobres da população e de ser preto, ele havia conseguido entrar na melhor faculdade de Direito do Rio de Janeiro. Esta pista reafirma-se na primeira reunião que o grupo de estudos dos estudantes protagonistas do filme - Dudu, Roberta, Maria e Matias - realiza na ONG da favela para discutir Foucault (!), enquanto aproveitam para "puxar fumo", deixando explícito o consumo generalizado de maconha entre eles. É uma cena exemplar, pois mostra Dudu, que é também o aluno-traficante, vestindo uma camiseta que estampa em letras garrafais sua marca e, portanto, sua origem social: Banana República. No caso do Brasil, é evidente que as camadas mais enriquecidas da população não têm dúvidas que essa marca não remete nem longinquamente a qualquer república das bananas, mas a uma marca cara, que não tem loja própria no Brasil, sendo comercializada nos Free Shops dos aeroportos ou em lojas próprias no exterior. $\mathrm{O}$ mesmo se pode dizer da cena na qual os alunos fazem uma passeata contra a morte de Roberta, já quase no final do filme, onde quase todos vestem uma camiseta branca com a foto da colega estampada, mas onde também a câmera, após passar por eles, estaciona sobre um último estudante que veste, ao contrário dos outros, apenas uma camisa polo amarela da marca Lacoste, outro símbolo de consumo de elite.

Somam-se a isso alguns outros indícios. A universidade que eles frequentam, apesar de não ser nunca nomeada, é absolutamente reconhecível, pelos seus famosos pilotis, como sendo a PUC do Rio de Janeiro, escola tradicional da burguesia carioca, instalada no bairro da Gávea. A festa da qual participam, realiza-se em uma ampla, moderna e arborizada casa com piscina, movida a DJ e na qual, não por acaso, toca-se, quando entram na festa Maria e Matias, a música Shiny Happy People da banda norte-americana REM, insistindo, para que ninguém tenha dúvidas, no famoso refrão: "Shiny Happy People holding hands, Shiny Happy People holding han$d s$, Shiny Happy People laughing...”. Se todos esses indícios não bastassem para caracterizar o grupo social dos "estudantes" como membros da burguesia carioca, dois diálogos vão reafirmar definitivamente tal percepção. O primeiro, e mais significativo, por ser uma fala interna ao próprio grupo, ocorre na aula em que os alunos vão apresentar o seminário sobre o livro Vigiar e punir, de Foucault, quando, no meio de acaloradas discussões sobre as formas de atuação da polícia, Roberta afirma que a polícia também trata mal pessoas como "eles", da classe média e da classe alta, dando como exemplo uma batida policial quando ela e duas colegas estavam indo para Búzios, recanto renomado de férias da burguesia carioca. A mesma Roberta que, quando da notícia de seu assassinato, é anunciada como sendo filha de um famoso empresário carioca. Por fim, outro aluno confirma essa visão ao falar que seu pai é juiz. Outra fala, proferida por Matias na passeata em memória de Roberta, reafirma essa visão no momento em que ele, exaltado, chama todos que lá estão de "bando de burguês safado".

Essa caracterização, absolutamente homogênea e que toma o todo pela parte, ao permitir que a caracterização de um pequeno grupo de seis pessoas possa remeter a todo um grupo social (os "estudantes"), que por suas vez remete sem mediações a toda uma classe social (a "burguesia"), numa espécie de metonímia social, é importante, pois ela remete diretamente à construção de uma das teses centrais do filme. Essa passagem direta acontece em vários momentos do filme, centrados principalmente na figura de Dudu, dublê de aluno, traficante e consumidor - o único que vemos consumir cocaína várias vezes no alto do morro junto com o chefe do tráfico, o Baiano. É ele também que abastece a universidade com pacotes de maconha que deixa para serem vendidos nas copiadoras da faculdade. É sintomático que, para mostrar a disseminação do consumo entre 
os estudantes, o rapaz que cuida das copiadoras reclama quando Dudu traz "apenas" dois pacotes da droga, pois "aquilo" estaria vendendo como água.

Por fim, e não menos significativo, é o momento, no início do filme, no qual outra ligação importante será feita. Ocorre na primeira cena da operação do Papa, ${ }^{4}$ quando a equipe do BOPE sobe o morro e, ao chegar a um ponto de agrupamento onde sabiam existir drogas, matam sem vacilar os dois traficantes armados que faziam a segurança do local. Um dos garotos ali presentes, quando pressionado pelos gritos insistentes e nada suaves do capitão Nascimento para que ele acuse quem era o portador da droga, diz em sua defesa que ele é "estudante". O que acontece a seguir é exemplar. Nascimento pega o garoto pelos colarinhos e, ao levá-lo para o lado de um dos mortos com um tiro no peito, enquanto enfia seu rosto no corpo sangrando e no buraco da bala, pergunta a ele aos brados quem é que fez aquilo. $\mathrm{O}$ "estudante" primeiro diz que não viu. Nascimento insiste que ele viu sim, repetindo várias vezes a pergunta. $\mathrm{O}$ "estudante" diz então que foi "um deles", um dos policiais. Nascimento, agora o estapeando no rosto, diz que "não foi não", que foi ele que matou aquele bandido, pois é ele ("os estudantes") que financia aquilo tudo, chamando-o repetidamente de maconheiro, entre outros palavrões.

Por fim, esse grupo social na construção do filme é o mais estereotipado de todos. Também por se constituir como grupo em uma sala de aula de "sociologia" em um curso de direito. Os livros que o professor aponta para os seminários são exemplares desse estereótipo: o que fica mais evidente como expressão dos interesses dos estudantes, Foucault, Vigiar e punir, mas também os que estão na lousa para serem escolhidos pelos alunos: Nietzsche, Genealogia da moral; Deleuze, Capitalismo e esquizofrenia; Durkheim, $A$ divisão do trabalho social; Weber, A ética protestante e o espírito do capitalismo; Marx, $O$ capital; Adam Smith, A riqueza das nações; Gilberto Freire, Casa grande e senzala; Lévy-Strauss, ${ }^{5}$ Raça e história, e $O$ mal-estar na cultura, de Freud. É curioso que a estereotipia na construção dos alunos comece pela estereotipia na construção do que seria um curso de sociologia para uma Faculdade de Direito, o que mostra uma frágil construção desse universo social e educacional dos estudantes, pois vários desses livros frequentam de maneira muito lateral os programas dos cursos de sociologia Brasil afora, além de ser difícil imaginar esses autores, de teorias tão diferentes entre si, unidos dessa forma genérica em um só curso. Além disso, o que é mais espantoso para olhares atentos, é o fato de se encontrar absoluta unanimidade contra a polícia, de maneira tão geral e tão avassaladora, em um curso de direito, o que mostra também a estereotipia em relação aos alunos e cursos das humanidades. Imagino que tal unanimidade já seria difícil de encontrar em classes de ciências sociais, o que torna sua proposição em alunos de direito ainda mais caricata, pois, além de tudo, não existe naquela classe nenhum, absolutamente nenhum, aluno legalista, aluno que, por mais que critique a ação exorbitante da polícia, defenda a manutenção das leis, pois, no caso da batida policial na estrada de Búzios, eles não chegaram exatamente a transgredir alguma lei. Mais do que a unanimidade, a ausência de qualquer legalismo por parte dos alunos faz com que aquela classe apareça de maneira homogênea e exemplar. Isso facilita, pela ligação efetuada com a ONG (meio pelo qual o filme pretende demonstrar as preocupações sociais dos estudantes, denominada pelo filme "consciência social"), a ligação orgânica e sem qualquer mediação dos estudantes com a burguesia e com o consumo/tráfico de drogas, como se todo estudante que tivesse preocupações sociais fosse diretamente um burguês maconheiro.

\section{Os traficantes e o enclave da ONG}

Um segundo grupo social se destaca na construção do filme, o que chamaremos precariamente de "favela", termo associado no Rio de Janeiro ao morro, local onde se encontra a maioria das favelas cariocas. ${ }^{6}$ Esse grupo é composto basicamente pelos "traficantes", sua expressão maior, e mais significativa, mas também pelos habitantes das favelas, pessoas que podem estar sob a "proteção" dos traficantes, ou do "movimento", maneira como se autodenominam no filme, mas que não são traficantes nem se misturam com eles, sendo em sua maior parte trabalhadores e não criminosos. A ONG é caracteriza- 
da mais como um enclave no morro do que como propriamente parte dele. Os traficantes, por sua vez, são construídos em uma chave explicativa social. Evidentemente, o filme não inocenta suas ações, mas sua raiz social se expressa desde o seu começo.

$\mathrm{Na}$ primeira cena em que aparece Baiano, o "chefe do morro", cheirando cocaína junto com "os estudantes", o narrador afirma que sabe como sua história vai terminar, mas não sabe como ela começou, imaginando apenas que ele teve uma infância difícil e que provavelmente entrou no tráfico por não ter mais nenhuma opção de vida. Essa tese não é mais retomada no filme a não ser lateralmente, quando Maria afirma que Baiano tem "consciência social" (a mesma coisa que se falará dos "estudantes"), o que lhe permite tomar conta dos habitantes do morro bem como autorizar o trabalho assistencial da ONG, que de resto não está bem delineado no filme. A população local também não está nada definida, apenas aparecendo lateralmente e, em geral, correndo pelos lados quando o BOPE avança ou nos conflitos armados com os traficantes, como no caso do baile funk. Fora isso, os traficantes aparecem sempre em conluios ou conflitos com a polícia e, na parte final do filme, como assassinos cruéis por matarem de maneira sádica Roberta, ${ }^{7}$ que morre com um tiro na cabeça antes de ser carbonizada, como também ocorre com seu namorado, responsável pela ONG, imolado em uma pilha de pneus numa referência direta ao assassinato do jornalista investigativo da rede Globo, Tim Lopes, em 2002.

Assim, se num primeiro momento os traficantes, materializados pela figura de Baiano, aparecem como frutos de uma sociedade que, por suas péssimas condiçóes sociais, leva parte da população a ver no crime a única saída possível para uma vida sem perspectivas, com o passar das cenas a figura de Baiano vai se alterando. Após o momento em que se descobre que Matias, namorado de Maria, é um policial, o traficante passa a perseguir e matar outros membros da ONG que, em princípio, não teriam de fato responsabilidade sobre isso, ressaltando certa aleatoriedade na culpabilização que os traficantes fazem das açôes que se abatem sobre eles. Exemplar nessa direção é o assassinato de Roberta e Rodrigues, que acontece sem qualquer mediação depois que Baiano mata Neto, amigo de
Matias, sem saber que ele era do BOPE, assinando com isso sua própria sentença de morte. A partir daí, os traficantes simplesmente vão até a sede da ONG e "justiçam" os dois, sendo que Maria, que foi quem levou Matias até eles, vai embora sem que ninguém lhe faça nada. Essa aleatoriedade é significativa, pois é ela que no limite legitima a ação do capitão Nascimento sobre eles, alguém que sabe de suas raízes sociais, mas que os culpa pela morte de Neto.

\section{A polícia militar}

O terceiro grupo é o da "polícia militar" do Rio de Janeiro, simbolizada pelo batalhão para onde são designados Neto e Matias como aspirantes a oficial. Aqui se cristaliza uma frase do capitão Nascimento, proferida no início do filme: no Rio de Janeiro, e na polícia em particular, ou a pessoa se corrompe, ou se omite, ou vai para a guerra, o que quer dizer na prática sair da polícia e ir para o BOPE, órgão sempre aludido nesse registro militar. Partindo desse pressuposto, as mediações que se farão entre os policiais militares são mais entre escalas de corrupção do que entre corruptos e não corruptos. É por isso que o filme apresenta a quase totalidade da polícia como corrupta, só alterando o montante da corrupção entre seus grupos internos, numa hierarquia de corrupção que acompanha ao mesmo tempo a hierarquia das patentes. Nada sabemos sobre os salários da polícia, a não ser quando o capitão Fábio afirma numa boate que policial nenhum vai subir morro para "tomar tiro" de bandidos por 500,00 "contos", ou seja, 500,00 reais.

Os policiais estão envoltos nas mais diversas formas de corrupção, desde o achaque mais "pé de chinelo" - feito quando não se paga um chope ou um café em um bar, bem como no caso do sargento do batalhão, que cobra uma "caixinha" para colocar o soldado na escala das férias -, passando pela cobrança por "segurança" nos estabelecimentos comerciais ou extorsão ligada a multas aplicadas pelo Estado, até as atividades mais "lucrativas" oriundas do recolhimento da "caixinha" do jogo do bicho (mais de 6 mil reais por semana) e da "caixinha" do tráfico de drogas, este realizado diretamente sob as 
ordens do comandante, cujo montante se imagina alto, mas que o filme não chega a declinar.

Essa hierarquia dos lucros se materializa em algumas cenas exemplares do filme. Uma mostra, por exemplo, o capitão Oliveira sair do quartel dirigindo um Omega CD, carro que seu soldo militar não permitiria adquirir ou manter - referência direta às suas fontes de renda "alternativas". Outra, mais singela, exibe uma conversa telefônica em que o capitão Fabio reclama com seu colega de patente Oliveira a apropriação indevida de seus pontos de achaque, dos bares de rua aos "acordos" para que não sejam multados carros estacionados irregularmente em frente de estabelecimentos dos "amigos". A cena mostra Oliveira almoçando com o comandante do Batalhão da Polícia Militar, ambos comendo como aperitivo um coquetel de camarão de proporções respeitáveis, degustado com evidente prazer, símbolo inexequível do bem-estar social gerado pelas atividades paralelas de extorsão e corrupção.

Se os policiais corruptos aparecem separados por essas duas categorias - do alto lucro ao "pé de chinelo”, da corrupção envolvendo quem em princípio a polícia deveria combater à extorsão mais comezinha -, a categoria dos que se omitem é pequena, numericamente insignificante e impotente, mas construída de forma simpática para o público, materializada no alto escalão na figura do tenente-coronel Estevão - que parece não participar de qualquer atividade desabonadora de sua função policial e que tenta defender Matias em relação à correção da mancha criminal avacalhada pelo comandante - bem como na imagem de dois subalternos, um cabo e um pracinha, que trabalham na oficina em meio a sanduíches de mortadela e motores novos trocados e vendidos clandestinamente por outros membros da corporação, delito relatado como comum e corriqueiro. Por fim, esse panorama se encerra nos personagens Matias e Neto, aspirantes a oficiais que por não se corromperem nem se omitirem partem, então, para a guerra, inscrevendo-se no curso do BOPE e transformando-se em policiais de elite.

\section{O BOPE e o capitão Nascimento}

O último grupo, e por isso o mais importante, é o do BOPE, que desde a primeira cena do filme já é apresentado como parte da polícia militar na teoria, mas constituindo, na prática, uma instituição policial completamente diferente. Esse grupo é corporificado na imagem de seu membro mais destacado, o capitão Nascimento. Curiosamente, é o grupo menos mediado no filme, sendo que praticamente tudo que podemos inferir sobre sua composição e organização advém do que vemos e ouvimos desse personagem, que se torna, portanto, sua expressão mais geral. $\mathrm{O}$ papel de Nascimento fica claro desde o princípio, pois é construído pela narrativa como o narrador fundamental do filme, que, por mais que aqui seja sempre pessoalizado e por isso obrigatoriamente interpretativo, acaba, no decorrer das cenas, aproximando-se dialeticamente de uma autorreflexão narrativa dos documentários performáticos, nos termos de Bill Nichols (2001, pp. 99-138). Ele mesmo se apresenta, logo de saída, como o policial de elite que é chamado para resolver os problemas quando a polícia falha, que sobe os morros em situação de conflito extremo, quando mais nenhuma outra força é capaz de resolver a situação. Entretanto, quando a história recua seis meses, e os personagens são apresentados em capítulos independentes, deparamo-nos com uma cena novamente exemplar, que começa com uma cartela preta onde se lê apenas o nome Nascimento. Ouve-se, enquanto ainda na tela vemos o intertítulo, uma voz calma e suave ao telefone dizendo com muito jeito e ternura: "meu amor, eu gostaria de estar com você também aí, mas eu estou trabalhando..." e após alguns segundos, "dá pra ouvir o coração dele aî́? Bota aí pr'eu escutar... Caramba, bate forte pra caramba né? Rapidão né? Meu amor, tenho que desligar que eu estou trabalhando aqui... Não precisa não que eu esquento no micro quando eu chegar... Eu também”. Esse diálogo absolutamente singelo, que pelo tom de voz poderia estar sendo realizado a partir de uma sala de escritório, ou de uma repartição pública qualquer, ou de um sofá, não só pelo tom de voz tranquilo que expressa, mas também pela aparente calma do lugar no qual imaginamos se realizar, apenas a partir do trecho da conversa que se refere às batidas do coração acompanhamos imagens que revelam onde de fato se encontra Nascimento: uma tocaia no alto de um morro, de noite, avistando policiais 
e traficantes que negociam armas apreendidas pela polícia em confrontos anteriores, o que reforça no espectador a corrupção que assola a polícia militar quase que como um todo e a função essencial que a tropa de elite tem a cumprir. Trata-se de um local absolutamente contrastante com o assunto e o tom da conversa que ali se delineava. Isso ressalta também, e por outro lado, o nível de cotidianidade que aquela situação representava para a vida do capitão do BOPE e de seus soldados.

As raízes sociais do capitão Nascimento também ficam claras no filme. Nada se diz sobre seu salário, mas as inúmeras cenas que se passam em sua casa permitem ao espectador perceber que apesar de sua alta patente Nascimento não é uma pessoa dotada de muitos recursos. Seu apartamento é acanhado, suburbano, de ambientes pequenos e escuros, o que demonstra uma construção de qualidades modestas e provavelmente cercada de outras equivalentes, em blocos de apartamentos de classe baixa, onde um prédio tira a luz dos outros e vice-versa. A sala é estreita, com um sofá para duas pessoas, em frente a uma estante onde se encontra uma TV de 20". A cozinha é acanhada, com uma geladeira de pequeno porte, um forno elétrico e uma máquina de fazer café. O cômodo mais mobiliado é o dormitório, que contém uma cama baú e um armário também modesto, do tipo que se compra em suaves prestações em lojas populares. Nessa acepção, e usando os conceitos propostos pelo filme, Nascimento, e todo o comando do BOPE, estaria na fronteira entre a baixa classe média e a alta classe baixa. Os outros soldados, evidentemente, são caracterizados como de estrato social mais baixo, como mostra o apartamento de decoração "minimalista" onde moram Neto e Matias, que só mostra na sala uma mesa pequena usada por Matias como escrivaninha e um saco de boxe com o qual Neto treina.

Nascimento incorpora também o "lado polícia" do BOPE, com seu treinamento violento e incursões no morro não menos agressivas. Mas o interessante é que esse lado mais afeito ao que se poderia esperar de um policial no Brasil, mais condizente com o senso comum a respeito da polícia brasileira, que bate antes de perguntar, que mata antes de ter certeza, é o tempo todo mediado pelas incessantes afirmações de Nascimento de que no BOPE não é isso que acontece, de que no BOPE a corrupção não entra. Mas Nascimento é mesmo um soldado especial. Se por um lado ele não hesita em fazer o que for preciso para descobrir, por exemplo, onde se esconde o traficante Baiano, numa espécie de vingança pela morte de Neto, momento repleto de cenas de tortura por meio de espancamento e sufocamento, mostradas sem mediações, por outro lado a narrativa sempre associa tais cenas com outras que mostram um Nascimento radicalmente diferente. Uma das mais expressivas se passa na maternidade, onde Nascimento foi ver, pela primeira vez, seu filho que acabara de nascer. É uma cena importante. Silenciosa, e curta, apenas mostra, de uma tomada por baixo e bem próxima, o rosto emocionado de Nascimento através do vidro, olhando para baixo em direção ao berço que não aparece para o espectador. A expressão chorosa de Nascimento é impagável, absolutamente igual à de todos os pais que olham seus filhos pela primeira vez pelo vidro dos berçários das maternidades, o que é ressaltado pela tomada realizada por uma câmara extremamente baixa, que aumenta e engrandece Nascimento e seu sentimento. E é nessa similitude que se encontra todo o segredo da construção desse personagem. Outras cenas se somam a essa, como a que mostra, por exemplo, Nascimento em casa trocando gentilmente a frauda do bebê, ou antes, no início do filme, quando passa suave e gentilmente a mão na barriga de sua esposa ainda grávida.

Por fim, na construção desse personagem, seguramente o mais complexo do filme, há ainda outro elemento bastante significativo. No momento de lazer, em que Nascimento escala uma parede de alpinismo urbano, ele fica paralisado no meio da subida para depois ser tomado por uma estranha taquicardia. Várias cenas dos preparativos de segurança para a chegada do Papa na cidade mostram um Nascimento nervoso, suando frio, com os braços serrados de tensão, cenas que remetem, associadas ao mal-estar durante o alpinismo e aos remédios que ele toma escondido de sua esposa, a um princípio de síndrome do pânico ligado à preocupação de que algumas operações poderiam não dar certo. Isso materializa, em suas ações, a ideia já explicitada pelo narrador de que não se pode esque- 
cer que policial também tem família, também tem medo de morrer.

Diferentemente de todos os outros personagens, há em relação a Nascimento uma quebra absoluta da estereotipia que veria num policial que tortura apenas um homem sádico, sem escrúpulos e sem sentimentos. Aqui, ao contrário, tudo investe contra essa percepção, pois se os outros grupos sociais são construídos de maneira homogênea e harmônica, com características simples e extrapoladoras, mais ou menos mediadas dependendo da situação - os "estudantes" como burgueses consumidores de drogas, os policiais militares como corruptos inveterados e os "traficantes" como pessoas frias e sem discernimento, o que, na narrativa, fugiria de qualquer tipo de justificação ligada às suas origens sociais - no caso do capitão Nascimento a mediação é permanente, investindo contra todos os lugares-comuns associados à polícia, mostrando suas ambiguidades e fraquezas, certezas e atitudes, que fazem com que ele seja de fato o único personagem complexo do filme, o único verdadeiramente humanizado, fundamento, nessa acepção, de sua capacidade de prender a atenção do espectador e, com isso, poder contar com sua simpatia, mesmo que crítica e mediada em alguns momentos.

Nessa direção, a constituição dos grupos sociais do filme aponta, por contraste, para a construção de um personagem pelo qual o público em geral possa ter mais empatia, ativando aquilo que Edgar Morin (1956) chamou de "fenômenos de projeção-identificação", pois, diferentemente do que se poderia pressupor pelo senso comum - a ideia de policial como herói, em tudo diferente de todos -, o que mostra o filme, e isso é essencial, é que as atitudes do capitão Nascimento, que não são nada heroicas, poderiam vir não de pessoas diferentes de todas mas, e aí significativamente, de pessoas absolutamente comuns. Dessa forma, ao lado de suas características como policial, o filme ressalta de maneira indelével os traços comuns e cotidianos de Nascimento, características que genericamente podem ser encontradas em todas as pessoas.

A esse processo deve-se somar mais um, que constitui uma mediação ao que de mais questionável faz Nascimento no decorrer do filme. Ele apresenta o BOPE e a si mesmo como não corruptos, e não se furta em nenhum momento de justificar a violência das ações do BOPE em face da brutalidade dos bandidos. Mas, evidentemente, a tortura não faz parte deste escopo. Com a tortura, o filme adota outro procedimento. De saída, ela é a mácula que envolve a história de Nascimento, sem a qual (afora sua crise de pânico e sem seus medos) ele seria o padrão perfeito de policial herói, defensor da lei e da família, carinhoso com uns, implacável com outros, sempre nobre e gentil. Nascimento, todavia, é cheio de falhas, que se exacerbam quando, no afã de encontrar um substituto, pois não aguenta mais aquela vida de guerra cotidiana (mais uma falha no estereótipo do herói), para poder dedicar-se à família que agora aumenta, resolve, desde o caso do fogueteiro justiçado pelos próprios traficantes, fazer justiça com as próprias mãos, de onde resulta a perseguição a Baiano por ter matado Neto, escolhido para ser seu sucessor. É claro que a tortura é indiscutível, condenável em todos os seus fundamentos, mas o filme faz aqui um elemento pesar a favor de Nascimento, principalmente se levarmos em conta o contraste já construído na conduta de Baiano e seu grupo. Em uma espécie de edição nacional de Jack Bauer, protagonista do seriado norte-americano 24 horas, Nascimento persegue e tortura para obter informações que levem ao paradeiro do traficante, mas com o "cuidado" de nunca torturar alguém que não tenha cometido algum crime. Ou seja, no enredo do filme é quase como se ele só torturasse quem no limite "merecesse". Se aqui se funda um lenitivo simbólico para que grande parte do público sinta empatia por esse personagem complexo, que une a humanização mais profunda com a bestialidade mais legitimada (no modo de ver do filme), ${ }^{8}$ por outro lado isso deixa a descoberto justamente o problema que, em princípio, critica, pois isso pode levar, como aconteceu em inúmeras críticas ao filme, a um clamor para que se generalizem posturas desse tipo, apresentadas como o "único" jeito de se devolver a paz a cidades com alta criminalidade e conflito, como o Rio de Janeiro.

A estratégia assumida pela narrativa combina de maneira eficaz aquilo que Bazin propôs como duas tendências opostas de construção de narrativas fílmicas: a crença na "imagem" ou a crença na "realidade". O personagem do capitão Nascimento 
é construído por sequências nessas duas direções. Mas, significativamente, a narrativa opta nas cenas de violência por uma construção centrada na velocidade e na articulação de planos rápidos pela montagem, portanto numa relação mais "distante" e "artificial" com o espectador. Em contrapartida, as cenas onde aparece o lado mais "humanizado", familiar e comum do protagonista são realizadas em planos-sequência de temporalidade estendida, com mais continuidade espaço-temporal e profundidade de campo. Seguindo Bazin, é bastante coerente que justamente tais cenas, que visam aproximar o personagem do espectador buscando criar maior sinergia com ele, sejam aquelas construídas utilizando-se das estratégicas narrativas que, segundo o autor, aumentariam o "coeficiente de ilusão", por apresentarem, como vimos, uma "estrutura mais realista" (Bazin, 1985, p. 67, grifo meu) e, portanto, mais propícia a provocar na plateia uma empatia mais acentuada com o personagem, reforçando seu "coeficiente de realidade", " portanto, a percepção deste Nascimento "humanizado" como alguém mais "real" do que o policial violento, mais "ficcional" e, em decorrência, mais "irreal”.

\section{Teses e antíteses sem síntese}

Nessa direção, o filme caminha por uma perigosa ambiguidade: por um lado, apresenta a tortura como algo questionável, que mancha a reputação ilibada de Nascimento, e do BOPE em geral; por outro, ao sugerir a legitimação dessa mesma tortura, aponta para uma quebra das relações de direito, o que pode facilmente ser lido como uma aposta na solução policial para problemas complexos demais para serem simplificados assim, como os de triste memória em tempos recentes em relação às torturas e aos assassinatos efetuados contra os adversários políticos durante a ditadura militar brasileira (1964-1985). Nesse sentido, essa tese do filme se esmaece em si mesma, pois se para muitos a solução policial pode ser atraente à primeira vista, daí alguns críticos acharem o filme fascista, o próprio filme acaba por mostrar que o $\mathrm{BOPE}^{10}$ só consegue ser o que é por permanecer uma instituição pequena, e pequena nunca conseguirá resolver o problema geral da criminalidade nas grandes cidades brasileiras.

Porém, ao mesmo tempo, o BOPE aparece como um lenitivo simbólico importante, o que pode causar estranheza para um público que vive em locais e países de baixos índices de criminalidade e que talvez perceba o filme apenas como a ação violenta da polícia, mas que parece fazer sentido para uma população imersa em uma violência urbana indescritível, para a qual não se enxergam soluções de curto prazo. É evidente que parte dos espectadores sempre lerá este filme na chave da apologia da violência policial, mas é importante entender por que pessoas que são também críticas a essa violência foram tomadas pelas ambiguidades do filme, passando mesmo a acreditar ser esta uma saída para a grave situação de segurança pública que atinge inúmeras cidades do país.

Isso remete à segunda tese de Tropa de elite, de que os consumidores de drogas são parte significativa do problema, sobretudo quando se trata de membros da burguesia brasileira. Aqui, onde não existe ambiguidade na mensagem do filme há um mérito e muitos problemas. O mérito é ter trazido à tona o outro lado da equação, normalmente ausente quando se toca no problema do tráfico de drogas, geralmente restrito ao par evidente polícia-traficante. O filme tenta mostrar que existe mais um polo nessa relação, polo esse que não pode ser desprezado nem esquecido. O problema está na demasiada homogeneização do grupo social "estudantes" - todos são burgueses, maconheiros e contra a polícia -, o que cria uma identidade bastante problemática entre traficante e consumidor, como se fossem elementos de idêntica importância na construção da questão. Aqui o estereótipo torna-se problemático, pois se o consumidor é parte da equação, então é preciso levar em conta que a diferença de nível entre traficante e consumidor é imensa. Ao apresentar sua tese de maneira homogênea, o filme despreza o fato de o problema do consumo ser de natureza diversa, de periculosidade diversa, de impacto social diverso. Ser traficante e ser consumidor não é a mesma coisa, sendo problemas distintos que exigem soluções diversas não são dois lados da mesma moeda, como o filme erroneamente induz a pensar. $\mathrm{O}$ problema existe, 
mas sua dimensão é completamente diferente, e sobre isso o filme se omite.

Em suma, sempre pensando em um público brasileiro, acostumado a vivenciar em seu dia a dia cenas de assalto e violência urbana perpetradas por bandidos ao lado da corrupção policial, bem como certa impotência social e institucional para dirimir o problema, a construção de três grupos sociais homogêneos no filme, em contraposição a um grupo muito mais mediado, mais complexo e por isso muito mais "humanizado", abriu portas para que um filme brasileiro sobre um assunto talvez pouco ou nada atraente tenha se tornado o maior sucesso de público do cinema no Brasil desde 2007, além de ter desencadeado na mídia incessantes debates e críticas radicais, inéditas em suas proporçôes e desatinadas em sua virulência.

\section{Notas}

1 Cf. Filme B (portal sobre mercado de cinema no Brasil). Disponível em <http://www.filmeb.com.br/por$\mathrm{tal} / \mathrm{html} /$ portal.php $>$.

2 Idem.

3 Vale a pena lembrar que Padilha repetia sempre em suas entrevistas que a leitura do filme pelo público estava equivocada quando diziam que o filme era politicamente de direita ou fascista, pois ele havia filmado Ônibus 174. É justamente desse tipo de interpretação que a metodologia utilizada propóe se distanciar.

4 Esta operação refere-se ao esquema de segurança a ser montado pelo BOPE durante a visita do Papa ao Rio de Janeiro.

5 O nome correto é Lévi-Strauss.

6 Não se utilizará aqui o termo "comunidade", pois isso demandaria discussões que fogem ao escopo deste trabalho, além de poder amenizar a percepção do preconceito que o filme pode mostrar.

7 Nas cópias que foram para o exterior, o sobrenome de Roberta era Lund - referência (e crítica) a Kátia Lund, coautora do documentário Notícias de uma guerra particular, sobre o BOPE e o tráfico de drogas nas favelas do Rio de Janeiro, que ficou famoso por entrevistar esses dois grupos em conflito sem hierarquizá-los ou moralizá-los, sem a pretensão de apontar alguma saída para o conflito. Na versão que passou em cinemas brasileiros o sobrenome foi alterado. Kátia Lund foi também codiretora de Cidade de Deus.
8 Morin afirma que: "A força de participação do cinema pode ensejar a identificação até aos desconhecidos, ignorados, desprezados ou odiados da vida cotidiana: prostitutas, negros para os brancos, brancos para os negros etc. Jean Rouch, que frequentou as salas de cinema da Gold Coast [hoje Gana], viu negros aplaudirem George Raft, o negreiro que, para escapar de seus perseguidores, joga ao mar sua carga de ébano" (1956, p. 110).

9 Desenvolvi esta questão em "O cinema documental como representificação: verdades e mentiras nas relações (im)possíveis entre representação, documentário, filme etnográfico, filme sociológico e conhecimento”, 2004.

10 No filme, o BOPE apresenta um quadro de cem membros. Segundo dados disponíveis em <http://www. tropasdeelite.xpg.com.br/Brasil-BOPE-PMERJ. html>, a instituição é composta por aproximadamente 420 soldados.

\section{BIBLIOGRAFIA}

AZEVEDO, Reinaldo. (2007), "Capitão Nascimento bate no bonde do Foucault". Veja, 2030, 17 out.

BAZIN, André. (1985), "L'évolution du langage cinématographique", in Qu'est-ce le cinéma?, Paris, Éditions Du Cerf, pp. 63-68. BLOC, Arnaldo. (2007), "Tropa de elite é fascista". Revista da Semana de O Globo, 19 set.-26 set.

BOSCOV, Isabela. (2007), "Recorde de contravenção". Veja, 2.030: 86, 17 out.

FRANCASTEL, Pierre. (1983), "L'objet filmique et l'objet plastique", in _Limage, la vision, l'imagination, Paris, Denöel/Gonthier, pp. 191-207.

FOUCAULT, Michel. (1994), “Qu'est-ce q'un auteur?", in , Dits et écrits, 19541988. Édition établie sous la direction de Daniel Defert et François Ewald. Paris, Gallimard, tomo I, pp. 789-821.

- (1971), L'ordre du discours. Paris, Gallimard.

JARVIE, Ian Charles. (1974), Sociologia del cine. Madri, Guadarrama.

MENEZES, Paulo. (2004), "O cinema documental como representificação: verdades e mentiras nas relações (im)possíveis entre representação, 
documentário, filme etnográfico, filme sociológico e conhecimento", in — Sylvia Caiuby Novaes et al. (orgs.), Escrituras da imagem, São Paulo, Edusp, pp. 21-48.

MORIN, Edgar. (1956), Le cinéma ou l'homme imaginaire. Paris, Minuit.

NICHOLS, Bill. (2001), "What types of documentary are there?", in , Introduction to documentary, Bloomington, Indiana University Press, pp. 99-138.

SORLIN, Pierre. (1977), Sociologie du cinéma. Paris, Aubin Michel.

XAVIER, Ismail. (1984), O discurso cinematográfico. São Paulo, Paz e Terra.

\section{Anexos}

Tabela 1

Cinema Nacional

\begin{tabular}{lllll}
\hline Título & Núm. Cópias & Núm. Salas & $\begin{array}{l}\text { Público Total } \\
(\mathbf{2 0 0 7 )}\end{array}$ & $\begin{array}{l}\text { Arrecadação } \\
(\mathbf{R} \$ \mathbf{2 0 0 7 )}\end{array}$ \\
\hline Tropa de Elite & 280 & 321 & 2.417 .193 & 20.393 .792 \\
\hline $\begin{array}{l}\text { A Grande Familia }-o \\
\text { Filme }\end{array}$ & 1 & 4 & 2.027 .385 & 15.476 .242 \\
\hline Primo Basilio & 3 & 9 & 838.726 & 6.376 .229 \\
\hline A Turma da Mônica & 1 & 8 & 631.656 & 3.925 .049 \\
\hline Xuxa Gêmeas & - & 22 & 572.264 & 3.229 .495 \\
\hline
\end{tabular}

Fonte: Cinema Brasil referente ao ano de 2007.

Tabela 2

Cinema Internacional

\begin{tabular}{lllll}
\hline Título & Núm. Cópias & Núm. Salas & $\begin{array}{l}\text { Público Total } \\
(\mathbf{2 0 0 7 )}\end{array}$ & $\begin{array}{l}\text { Arrecadação } \\
(\mathbf{R} \mathbf{2 0 0 7 )}\end{array}$ \\
\hline Homem - Aranha 3 & 397 & 869 & 6.141 .200 & 48.941 .000 \\
\hline Shrek Terceiro & 575 & 705 & 4.688 .200 & 35.687 .000 \\
\hline Harry Potter 5 & 725 & 775 & 4.263 .800 & 31.756 .000 \\
\hline Piratas do Caribe 3 & 679 & 789 & 3.826 .700 & 30.837 .000 \\
\hline Uma Noite no Museu & 453 & 502 & 3.030 .300 & 22.904 .000 \\
\hline 300 & 462 & 511 & 2.733 .900 & 22.811 .000 \\
\hline Tropa de Elite & 280 & 321 & 2.417 .193 & 20.393 .792 \\
\hline
\end{tabular}

Fonte: Cinema Brasil referente ao ano de 2007. 


\section{TROPA DE ELITE: PERIGOSAS AMBIGUIDADES}

\section{Paulo Menezes}

Palavras-chave: Tropa de elite, violência, sociologia do cinema, violência policial.

Este artigo visa discutir as relaçôes entre imagem cinematográfica e produção de conhecimento na direção da constituição de um imaginário social que funda e orienta interpretaçóes e avaliaçóes sobre o mundo e os fenômenos sociais que o constituem. Discute como os filmes constroem uma determinada forma de apreensão dos fenômenos sociais por meio da complexa elaboração de um imaginário que vai servir de base para que se olhe o mundo sob determinado recorte e a partir de determinados valores. Para materializar esta perspectiva em uma análise concreta, toma-se o filme Tropa de Elite, de ampla repercussão nacional e internacional, para investigar os artifícios e opções de constituição de personagens e de estruturação de narrativa utilizados pelo diretor no sentido de apresentar enquanto filme sistemas relacionais e hierarquias que recortam $\mathrm{e}$ generalisam determinados personagens e grupos sociais apresentados ao público de forma coesa e significativa ao mesmo tempo que elidem a percepçáo dos valores que orientaram o recorte e a reconstrução do mundo nos moldes que o filme realiza. Nessa direção o artigo empreende um destrinchamento destas construções revelando os valores que estão fundando essas construçóes e que terminam por orientar as valoraçóes e, no caso, também as avaliações que o filme realiza mas que tenta não deixar explícitas.

\section{TROPA DE ELITE: DANGEROUS AMBIGUITIES}

Paulo Menezes

Keywords: Tropa de Elite; Violence; Sociology of the movies; Police violence.

This article aims at discussing the relations between cinematographic image and production of knowledge in shaping a social imaginary that founds and orients interpretations and evaluations about the world and the social phenomena of which it is constituted. It discusses how movies produces a certain form of apprehending social phenomena by means of a complex elaboration of an imaginary that will serve as a basis for seeing the world under a certain framing and on the basis or certain values. In order to materialize this perspective, the film Tropa de Elite, of large national and international repercussion, is taken as object of a concrete analysis in order to examine the artifices and options of the director in constructing characters and structuring the narrative. Such artifices and options allow him to present, as a movies, relational systems and hierarchies that delimit and generalize certain characters and social groups presented in a cohesive and meaningful form, simultaneously eliding the perception of the values orienting the delimitation and the construction of the world as accomplished by the film. In this sense, the article undertakes a disentanglement of such constructions, revealing the values on which they are founded, which end up in orienting the implicit value assessment and, in this case, also the evaluations made by the film, but that it try to avoid making explicit.

\section{TROUPE D'ÉLITE : DE DANGEUREUSES AMBIGÜITÉES}

\author{
Paulo Menezes
}

Mots-clés: Troupe d'élite; violence; sociologie du cinéma; violence policière.

Le but de cet article est de discuter les rapports entre l'image cinématographique et la production du savoir vers la constitution d'un imaginaire social qui sert de base et qui oriente les interprétations et les évaluations à propos du monde et des phénomènes sociaux qui le constituent. L'article présente un débat sur la façon par laquelle les films construisent une certaine apréhension des phénomènes sociaux par une construction complexe d'un imaginaire qui va servir de base pour un regard sur le monde d'après une certaine perspective et à partir de valeurs établies. Pour matérialiser cette perspective en une analyse concrète, nous prenons l'exemple du film Tropa de Elite (Troupe d'Élite), qui a eu une grande répercussion nationale et internationale. Nous l'utilisons pour étudier les artifices et les options de construction de personnages et de structuration de la narrative utilisées par le directeur en vue de présenter, en tant que film, les systèmes de relations et de hiérarchies qui recoupent et qui généralisent certains personnages et groupes sociaux présentés au public de façon cohérente et significative. Mais, en même temps, ils suppriment la perception des valeurs qui orientent le découpage et la reconstruction du monde suivant les modèles que le film présente. L'article entreprend ainsi un découpage de ces constructions qui révèle les valeurs qui les fondent et qui finissent par orienter les évaluations et, dans ce cas, les estimations faites par le film de façon non explicite. 